\title{
Considerations for collecting and documenting FGM/C data by health care providers
}

Dennis Matanda

Population Council

Follow this and additional works at: https://knowledgecommons.popcouncil.org/departments_sbsr-rh

Part of the Demography, Population, and Ecology Commons, Family, Life Course, and Society Commons, Gender and Sexuality Commons, International Public Health Commons, and the Medicine and Health Commons How does access to this work benefit you? Let us know!

\section{Recommended Citation}

Matanda, Dennis. 2020. "Considerations for collecting and documenting FGM/C data by health care providers," Evidence to End FGM/C: Research to Help Girls and Women Thrive. Nairobi: Population Council. 


\section{Considerations for Collecting and Documenting FGM/C Data by Health Care Providers}

The Evidence to End FGM/C programme consortium generates evidence to inform and influence investments, policies, and programmes for ending female genital mutilation/ cutting in different contexts.

Population Council Lead Institution

Africa Coordinating Centre for the Abandonment of Female Genital Mutilation/Cutting, Kenya (ACCAF)

Global Research and Advocacy Group, Senegal (GRAG)

MannionDaniels Ltd. (MD)

Population Reference Bureau (PRB)

University of Washington (Prof Bettina Shell-Duncan)

University of California, San Diego (Dr. Gerry Mackie)

Funded by

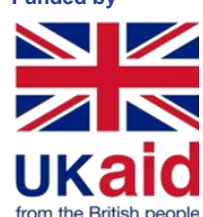

\section{INTRODUCTION}

Data on FGM/C are rarely collected in health facilities (Dirisu et al., 2020; Johansen et al., 2018; Kimani and Okondo, 2020), yet, routine collection of facility-based data on FGM/C status through other health-seeking visits (e.g., during antenatal care) is not only considered good medical practice (WHO, 2018), but can be an important source of data. Clinical data on FGM/C can also inform efforts to manage complications (Johansen et al., 2018). As illustrated in Figure 1, clinical exams provide an opportunity to identify women and girls who have undergone $\mathrm{FGM} / \mathrm{C}$, which is an important step in aiding the prevention of chronic complications that can be difficult and expensive to manage later in life. Clinical exams also make it possible to refer those with FGM/C-related complications for specialised treatment. The information gathered during clinical exams may be more reliable as it enables the examiner to observe and confirm whether the woman has been cut or not, and document more detailed information about the different types of FGM/C. It may also reduce errors related to misreporting and underreporting that is common when women are asked to report on their experience with FGM/C. Clinical visits also present an opportunity to discuss prevention of the practice. In instances where women seeking asylum due to $\mathrm{FGM} / \mathrm{C}$ are required to prove their status, physical exams can provide supporting evidence.

Figure 1. Advantages of conducting clinical examinations for FGM/C

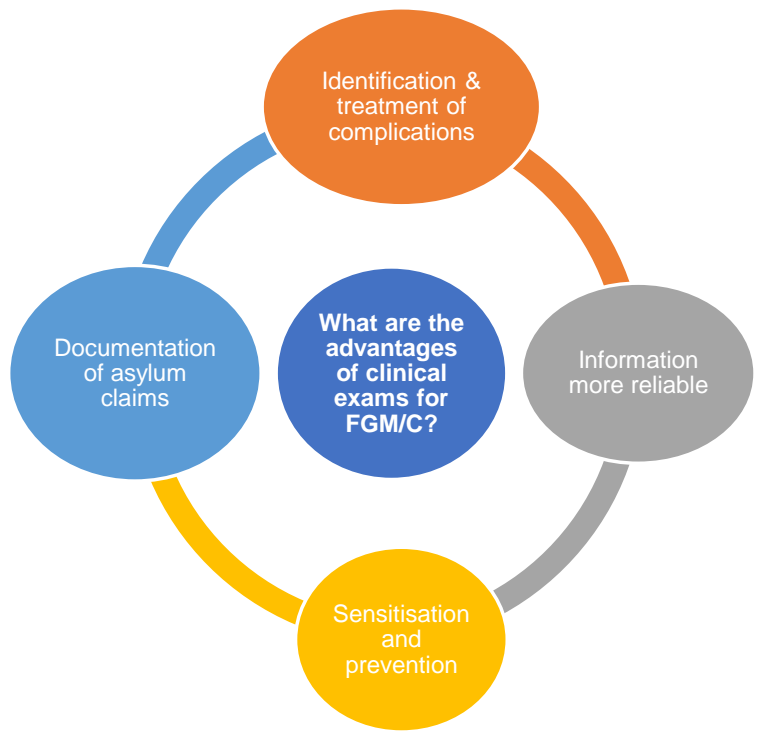

Source: Matanda, D. 2020. "Measurement of female genital mutilation/cutting status: Perspectives from healthcare providers, policymakers, programme implementers and researchers." Evidence to End FGM/C: Research to Help Girls and Women Thrive. New York: Population Council. 


\section{ABOUT THIS NOTE}

This note outlines critical considerations for collecting and documenting FGM/C data by health care providers. We draw on existing literature and key findings from a study conducted by the Evidence to End $F G M / C$ research consortium that aimed to gather data from professionals working in the area of $F G M / C$ about their views and experiences in the measurement of FGM/C prevalence (Matanda, 2020).

\section{KEY CONSIDERATIONS}

1. Health care workers need adequate training on FGM/C: Even though considered the gold standard approach in data collection on FGM/C (Elmusharaf et al., 2006), findings from studies that have investigated the validity of physical examination have shown that the routine collection of $\mathrm{FGM} / \mathrm{C}$ data may be hindered by several factors. First, clinicians may incorrectly report women's FGM/C status because they are rarely trained on the practice. Second, there is substantial variability in the type of $\mathrm{FGM} / \mathrm{C}$ performed across and within countries, which can make it difficult to ascertain the type of FGM/C. Although the World Health Organization has developed a clinical handbook to help clinicians manage health complications from $\mathrm{FGM} / \mathrm{C}$ (WHO, 2018), in many settings, there are no guidelines on how to conduct physical exams especially when dealing with women likely to have undergone FGM/C. Finally, examination is an invasive procedure and is likely to be traumatic to women and girls if handled unprofessionally - especially in cases where it is done without consent of the patient.

\section{"It is very intrusive... why should women/girls undergo unnecessary pelvic exams for what - documentation purposes? ... unless they are treating women for gynaecological check-ups or ailments or during pregnancy, I see no reason why health care providers should be examining anyone to report FGM/C status. You may find instances where girls are subjected to these physical exams without their consent, which can also be harmful." - Researcher, Kenya}

2. Punitive anti-FGM/C laws can cause fear among FGM/C survivors and antagonise the relationship between health care providers and patients: In contexts where $\mathrm{FGM} / \mathrm{C}$ is illegal and reporting by health care providers is mandatory, FGM/C survivors may avoid routine visits to health facilities. Punitive anti-FGM/C laws cause fear among $\mathrm{FGM} / \mathrm{C}$ survivors and antagonise the relationship between health care providers and patients. In such an environment, FGM/C survivors are likely to develop poor health-seeking behaviours, especially for cases that involve physical examination of their genitals. Physical examination could amount to ethnic/racial profiling if the exercise does not apply to every woman/girl in a given setting. Immigrant women from countries that have traditionally practised $\mathrm{FGM} / \mathrm{C}$ are in most cases specifically targeted for physical examinations with the aim of assessing their FGM/C status. This approach may be considered discriminatory as it profiles individuals based on their background information such as ethnicity and country of origin. Physical examination could also be a source of shame and discomfort among $\mathrm{FGM} / \mathrm{C}$ survivors. In contexts where $\mathrm{FGM} / \mathrm{C}$ is frowned upon, women who have undergone $\mathrm{FGM} / \mathrm{C}$ may feel uncomfortable undergoing the physical exam because they fear being stigmatised. "Probably many asymptomatic FGM survivors avoid routine visits and therefore there may be an
overreporting of symptom prevalence. This is especially true in countries where reporting is mandatory, and patients know it." - Health care provider, USA

3. Inability of the health system to facilitate documentation of $\mathrm{FGM} / \mathrm{C}$ can be a hinderance to clinical examinations: Health systems must offer an enabling environment to support the documentation of $\mathrm{FGM} / \mathrm{C}$ by providing requisite tools for recording and documenting $\mathrm{FGM} / \mathrm{C}$ cases; training health care personnel on the documentation of $\mathrm{FGM} / \mathrm{C}$; and ensuring the availability of clear policy guidelines to support FGM/C-related data collection. Health systems must also address the 
ethical challenges related to the documentation of FGM/C cases. These challenges include adherence to laws that require health care providers to report FGM/C cases while at the same time attending to the needs of the patient; doing more harm to the child by reporting FGM/C, which can lead to the child being separated from parents; making physical examination a requirement for accessing other benefits; conducting physical exams without consent from women; intrusion of a girl's or woman's privacy that can cause trauma especially for underage girls; and challenges with consent and implementation of physical exams outside a health facility setting.

\section{It is feasible to use images in identifying and classifying the different types of} FGM/C: Given the debate around classification of the various types of FGM/C, images/pictorial presentations can help providers identify and classify $\mathrm{FGM} / \mathrm{C}$. Anatomical drawings can be very helpful in improving the documentation of the extent of FGM/C. Matanda (2020) and Abdulcadir et al (2016) found that images were considered helpful both in scenarios where the health care provider was expected to observe and record $\mathrm{FGM} / \mathrm{C}$ cases, and in situations where a woman was shown the images to identify the type of FGM/C. Images are also useful in training health care providers about the anatomy of the woman's genitalia and the alterations that can occur due to FGM/C. However, the use of images could equally raise ethical challenges such as respecting cultures that are not comfortable with public show of images representing what is considered private. Further, only showing photos of women from particular ethnic groups with extreme forms of $\mathrm{FGM} / \mathrm{C}$ could raise ethical questions.

\section{CONCLUSION}

In recent years, there has been a marked increase in the amount of systematically collected information on $\mathrm{FGM} / \mathrm{C}$ and factors responsible for the continuation of the practice. This information has been collected through a range of methods, including medical case studies, small-scale surveys and larger national surveys, such as the Demographic and Health Surveys (DHS) and Multiple Cluster Indicator Surveys (MICS) that include a module with questions on $\mathrm{FGM} / \mathrm{C}$. While national-level surveys, especially the DHS and MICS, have greatly increased understanding about the practice, there are important limitations. National surveys such as the DHS and MICS are only implemented about once every five years resulting in limited real-time data. Additionally, these types of surveys may lead to misreporting and underreporting, especially in contexts where there are laws against the practice. Cognisant of the highlighted considerations, health facilities have a huge potential in filling this gap through routine collection of $\mathrm{FGM} / \mathrm{C}$ data at clinical level. This data will not only be crucial in documenting the incidence of $F G M / C$, but will also enhance the monitoring of quality of care, provide a rich source of data for research, and inform efforts to prevent $\mathrm{FGM} / \mathrm{C}$ and manage complications of women and girls living with FGM/C.

\section{REFERENCES}

Abdulcadir, J., Catania, L., Hindin, M. J., Say, L., Petignat, P., \& Abdulcadir, O. (2016). Female genital mutilation: A visual reference and learning tool for health care professionals. Obstetrics and Gynecology, 128(5), 958963(6). https://doi.org/10.1097/AOG.0000000000001686

Dirisu, O., Adetunji, A., Adediran, M., \& Obianwu, O. (2020). A diagnostic assessment of health systems response to FGM/C management and prevention in Nigeria. Evidence to End FGM/C: Research to Help Girls and Women Thrive. New York: Population Council.

Elmusharaf, S., Elhadi, N., \& Almroth, L. (2006). Reliability of self reported form of female genital mutilation and WHO classification: Cross sectional study. British Medical Journal, 333(7559), 124.

https://doi.org/10.1136/bmj.38873.649074.55

Johansen, R. E. ., Ziyada, M. ., \& Shell-Duncan, B. (2018). Health sector involvement in the management of female genital mutilation/cutting in 30 countries. BMC Health Services Research, 18(240).

https://doi.org/https://doi.org/10.1186/s12913-018-3033-x

Kimani, S., \& Okondo, C. (2020). A diagnostic assessment of health system's response to female genital mutilation/cutting management and prevention in Kenya." Evidence to End FGM/C: Research to Help Girls and Women Thrive. New York: Population Council.

Matanda, D. (2020). Measurement of Female Genital Mutilation/Cutting Status: Perspectives from Healthcare Providers, Policymakers, Programme Implementers and Researchers. Evidence to End FGM/C: Research to Help Girls and Women Thrive. New York: Population Council.

WHO. (2018). Care of girls and women living with female genital mutilation. A clinical handbook. Geneva: World Health Organization.

Acknowledgements: This guidance note was developed by Dennis Matanda with input and guidance from Caroline Kabiru.

Suggested citation: Evidence to End FGM/C: Research to Help Girls and Women Thrive Research Programme. 2020. Guidance Note. Considerations for collecting and documenting FGM/C data by health care providers. New York: Population Council. 